\title{
A novel approach for propagation of recalcitrant pistachio cultivars that sidesteps rooting by ex vitro grafting of tissue cultured shoot tips
}

\author{
J.A. Marín, E. García, P. Lorente, P. Andreu and A. Arbeloa \\ Estación Experimental de Aula Dei-CSIC. \\ Avenida Montañana 1005. \\ 50059 Zaragoza. \\ Corresponding autor \\ e-mail: jmarin@eead.csic.es \\ telephone: +34 976716128 \\ fax: +34 976716145 \\ Plant Cell, Tissue and Organ Culture (DOI) 10.1007/s11240-015-0871-7
}

\begin{abstract}
Pistachio (Pistacia vera L.) cultivars need to be grafted on suitable rootstocks for their propagation, but grafting success is uncertain, preventing producers to meet plant demand. Thus, there is a need for a better grafting method that in addition to increase success rate, allows us an early detection of success. Here, we have developed an alternative grafting technique that achieves these goals using young potted seedlings of terebinth rootstock and reduced size micropropagated scions from commercial cultivars. During micropropagation of pistachio cultivars we studied the effects of the application of antioxidants together with the growth regulators meta-Topolin and paclobutrazol on in vitro cultures to overcome the issues identified in the different phases of micropropagation: culture initiation, multiplication and rooting. Grafting succeeded using scions derived from in vitro cultured micro-shoots both from acclimated and non-acclimated plants. With this protocol, up to $75.7 \%$ successful grafts were obtained, and grafted plants resumed growth from day 3, being ready for transplant a few months later. Sustained on our results, we present a simple and reliable system to reduce production time by ex-vitro grafting of shoottips from in vitro cultures onto 4 weeks old terebinth (Pistacia terebinthus L.) rootstock seedlings grown in pots.
\end{abstract}

Keywords

Pistacia vera. Clonal propagation, In vitro culture, Shoot Tip Necrosis, meta-Topolin, Paclobutrazol.

Introduction

Pistachio is an expanding crop in Spain where the cultivation area is increasing steadily. However, pistachio plant production does not match the demand, limiting production growth. Pistachio cultivars need to be grafted onto suitable rootstocks for an adequate development, but the lack of clonal rootstocks well adapted to the different environmental conditions is a drawback of this crop. Pistacia vera seedlings, in spite of being compatible and very vigorous, are not used as rootstocks in western countries due to sensitivity to soil-borne diseases. Other vigorous rootstocks, such as the hybrid UCB1 (Pistacia atlantica $x$ P.integerrima) or P. atlantica are not adequate to the main production areas of Spain due to the lack of adaptation to cold winters and dry summers (Ferguson et al. 2005). There, a suitable rootstock is the terebinth tree (P. terebinthus), an autochtonous and less vigorous tree propagated by seeds, well adapted to cold winters, resistant to Armillaria, but sensitive to Verticillium (Ferguson et al. 2005). Seedlings have to be grafted after two years of growth, in summer, once they reach a diameter close to $15 \mathrm{~mm}$ (Guerrero et al. 2007a). This lack of vigor in the rootstock may be related to the uncertainty of grafting success that originates irregular orchards (Guerrero et al. 2002; 2007b). A common practice is to re-graft unsuccessful grafts one month later (Guerrero et al, 2007a). 
Thus, there is a need to develop a grafting technique that allows us both to improve the rates of success and to transplant to the orchard only successful grafts detected earlier. Instead of budding, in this work we propose an alternative pistachio propagation system based on the development of a bench grafting method using micropropagation techniques to obtain reduced size plants, so that the diameter of the scions matched that of the seedlings to perform a cleft grafting.

In vitro culture of pistachio has been initiated generally from germinated seeds of different varieties, since it is a difficult species to multiply in vitro, and only few reports are based on adult material from $P$. vera cultivars: 'Antep' (Onay 2000); 'Atli' (Tilkat and Onay 2009); 'Mateur' (Abousalim and Mantell 1992; Chatibi et al. 1997; Dolcet-San Juan and Claveria 1995); and 'Siirt' (Onay et al. 2004). Nevertheless, the protocols described in these reports failed when applied to the cultivars used here.

During the establishment of aseptic cultures of pistachio and other woody plants, tissue browning frequently results in the early death of explants (Abousalim and Mantell 1994; Barghchi and Alderson 1996; Bairu et al 2009a, 2009b; Onay et al. 2007; Tabiyeh et al. 2006). In spite of the extent of this problem, no conclusive explanation has been reported, but the role of polyphenol oxidase activity in browning and its inhibition by antioxidants have been suggested (Leng et al. 2009; Pizzocaro et al. 1993).

At multiplication phase, shoots of pistachio often show apex necrosis and lack of branching (Barghchi and Alderson 1996; Bairu et al. 2009b), reducing the production of high quality long shoots, needed for rooting. Plant growth regulators play a role on shoot necrosis (Bairu et al. 2009b), thus, here we test whether meta-Topolin $(m \mathrm{~T})$, a cytokinin that improved the quality of $P$. vera shoots from cultures derived from seedlings (Benmahioul et al. 2012), keeps shoot quality, reducing the extent of apex necrosis in cultures of mature $P$. vera shoots.

While at rooting stage, poor rooting rates together with lack of synchrony and the decay of rooted shoots hinder success (Benmahioul et al. 2012; Chatibi et al. 1997; Tilkat and Onay 2009). Rooting and acclimatization may be hampered by low shoot quality, so we tried to keep shoots healthy during the rooting phase, where shoots with no apical growth and necrosis, leaf yellowing and defoliation occurred.

To improve shoot quality and rooting different treatments have been used successfully in some species: the increase of transpiration of shoots by aeration (García et al. 2011b); the auxin protection against oxidation with vitamins C and E (Lis-Balchin 1989) or phloroglucinol (De Klerk et al. 2011); and the use of the antigibberellin paclobutrazol (Davis et al. 1985).

Grafting applying tissue culture techniques have been performed previously in pistachio in different ways, but not for propagation purposes. Micrografting 'Mateur' cultivar scions $(8-10 \mathrm{~mm})$ onto in vitro germinated seedlings of $P$. vera gave successful grafts, but poor shoot development (Abousalim and Mantell 1992). Better results were obtained by micrografting the cultivar 'Siirt' onto in vitro seedlings for rejuvenation purposes, but success was related to scion size (Onay et al. 2004). On the other hand, ex vitro grafting of shoots produced in vitro is an uncommon technique that has been used mainly to rescue transgenic rootless Citrus shoots (Yang et al. 2000; Weber et al. 2003) or avocado somatic embryos lacking the root system (Raharjo and Litz 2005). Our approach differs from those previously reported in the use of shoot cultures, initiated from field-grown commercial cultivars, as the source of suitable scions to be grafted ex vitro onto seedlings few weeks after germination to take advantage of their growing potential. This technique would have a practical application as an alternative method of pistachio plant propagation.

In this paper, we report the effect of different factors on the different phases of micropropagation to overcome the identified issues in the different phases of micropropagation of pistachio cultivars to develop a suitable protocol that allows us to get micropropagated plants of reduced size able to be grafted ex vitro onto seedling rootstocks few weeks after germination. We tested here 1) the effect of an antioxidant mixture to prevent explant browning at culture initiation; 2) the effect of $m \mathrm{~T}$, instead of BAP, to improve shoot quality during multiplication; and 3) the effect of different treatments affecting shoot health or auxin effect to improve root formation. Thereafter ex vitro grafting using either acclimated or non-acclimated shoot tips from in vitro cultures were performed onto terebinth seedlings. Thus, the final goal is to improve the grafting technique accelerating scion sprouting for fast, reliable and inexpensive plant production. 
Materials and Methods

Plant materials

Actively growing shoots from forced sprouts or from field-grown trees of different cultivars ('Kerman', 'Larnaka', 'Peters', and 'C-Especial') were kindly provided by Dr J.F. Couceiro from C.A. El

Chaparrillo, Ciudad Real (Spain) in spring 2011, and shoots of the selection AD15 were taken from the "Campus de Aula Dei" at Zaragoza (Spain). All shoots were taken from trees growing in the field for at least 10 years. Explants were immediately submerged into an antioxidant solution $(1 \mathrm{mM}$ ascorbic acid + $1 \mathrm{mM}$ citric acid) for $15 \mathrm{~min}$. Browning caused the early death of explants of all cultivars except those of $\mathrm{AD} 15$, thus culture initiation was repeated maintaining the explants in the antioxidant solution for longer periods ( $7 \mathrm{~h}$ for 'Peters', 'Kerman', and 'Larnaka', or $24 \mathrm{~h}$ for 'C-Especial').

Seedlings of terebinth (P. terebinthus L.) were obtained from wild mature seeds. Seeds were peeled, washed in distilled water, dried, and cold stored at $4-5^{\circ} \mathrm{C}$ for at least 5 months (García et al. 2011a). Seeds were then sowed in forest cells containing Pindstrup substrate, a proprietary mixture of peat:perlite (Pindstrup Mosebrug S.A.E. professional substrate) and maintained in a greenhouse.

Culture media and culture conditions

After the antioxidant treatment, sections of 2-4 nodes without leaves were washed for 1 hour under running tap water before $15 \mathrm{~min}$ surface disinfestation with a bleach-detergent solution $\left(5 \mathrm{~g}\right.$ active $\left.\mathrm{Cl} \mathrm{l}^{-1}\right)$ or $0.05 \%(\mathrm{w} / \mathrm{v}) \mathrm{HgCl}_{2}$. Nodes ( $\mathrm{n}=48$ per disinfection treatment, or 33 in AD15) were rinsed 3 times with sterile deionized water and kept in antioxidant solution until they were cultured in vitro (García et al. $2011 \mathrm{~b}$ ) in modified DKW medium (Driver and Kuniyuki 1984) with $56.8 \mu \mathrm{M}$ ascorbic acid, $5 \mu \mathrm{M}$ BAP, $0.5 \mu \mathrm{M}$ IBA and $3 \%(\mathrm{w} / \mathrm{v})$ sucrose. $\mathrm{pH}$ was adjusted at 5.7 with $1 \mathrm{~N} \mathrm{KOH}$ before adding $0.7 \%(\mathrm{w} / \mathrm{v})$ Difco-Bacto agar. Medium $(10 \mathrm{ml})$ was dispensed into $105 \mathrm{~mm}$ x $25 \mathrm{~mm}$ glass test tubes, covered with white polypropylene caps and autoclaved for $20 \mathrm{~min}$ at $121{ }^{\circ} \mathrm{C}(0.1 \mathrm{MPa})$. Cultures, one node per tube, were maintained at $24 \pm 1{ }^{\circ} \mathrm{C}$ under cool-white fluorescent tubes $\left(35 \mu \mathrm{mol} \mathrm{s}{ }^{-1} \mathrm{~m}^{-2}\right.$ PAR), with a $16-\mathrm{h}$ photoperiod. Frequent transfers to fresh medium were made to relieve the harmful effect of browning. Bud break percentages were recorded. New shoots were transferred to the same medium (30 ml) in Sigma baby food jars (V8630) and then subcultured every 3 weeks onto the same medium. A modified Long and Preece medium (LP, Long et al. 1995) that combines mineral salts formulations from WPM (Lloyd and McCown 1981) and DKW media was used to improve the micropropagation of 'Kerman', providing better quality shoots than DKW (Marín et al. 2015).

Cytokinins effect on Shoot Quality during multiplication

Explants (shoot tips about $10 \mathrm{~mm}$ long) were subcultured to multiplication medium at 3-week intervals. During multiplication, the effect of meta-Topolin ( $m \mathrm{~T}, 6-(3-$ Hydroxybenzylamino) purine), instead of BAP, on shoot quality and the appearance of shoot tip necrosis (STN) was tested at the same concentration $(5 \mu \mathrm{M})$, but supplemented with a lower concentration of kinetin $(2 \mu \mathrm{M})$ to compensate the lower number of shoots produced by $m \mathrm{~T}$ compared to BAP (Werbrouk et al. 1996). Pistachio shoot tips (1 $\mathrm{cm}$ length) developed new shoots at the swelled base of the shoots after several weeks of culture. Percentages of shoots affected by STN, length of shoots, and number of new shoots after 6 weeks of culture were recorded ( $\mathrm{n}=196$ per treatment for AD15; $\mathrm{n}=35$ for 'Kerman' and 'Peters').

Factors affecting rooting

Healthy shoots (at least $20 \mathrm{~mm}$ long) were excised and transferred to rooting medium removing the lower leaves. Rooting standard medium was the same but with macronutrients reduced to half concentration, without ascorbic acid and cytokinins, and with IBA at $5 \mu \mathrm{M}$. Sigma Phytacon ${ }^{\mathrm{TM}}$ Vessels (P5557) were used with $100 \mathrm{ml}$ medium. The effects of different factors on rooting were studied to improve the lack of rooting with the standard medium using 10 shoots per jar and per treatment. The whole experiment was repeated 3 times $(n=30)$ and rooting percentages were calculated.

1) Effect of aeration and kinetin on shoot quality.

Increased aeration to favor leaf transpiration was carried out by using vented lids. A low concentration of kinetin $(2 \mu \mathrm{M})$ was added to the rooting medium to improve shoot quality. 


\section{2) Effect of antioxidants and phloroglucinol on rooting}

The effect of antioxidants and phloroglucinol on rooting was tested by adding these compounds to the rooting medium. Vitamin $\mathrm{C}$ (ascorbic acid) at $56.8 \mu \mathrm{M}$, vitamin $\mathrm{E}$ ( $\alpha$-tocopherol) at $2.3 \mu \mathrm{M}$ and phloroglucinol at $0.79 \mu \mathrm{M}$ were tested separately. These compounds were added to the rooting medium before autoclave.

\section{3) Effect of paclobutrazol}

Paclobutrazol, an inhibitor of GA, was tested by adding $3.4 \mu \mathrm{M}$ to the rooting medium. Due to the observed beneficial effect of paclobutrazol, it was further compared to $6.8 \mu \mathrm{M}(\mathrm{n}=30)$.

Acclimatization

Healthy AD15 rooted shoots were washed and transplanted to jiffy strips filled with Pindstrup substrate, and kept at high RH for acclimatization in a plastic tunnel in the greenhouse, increasing the exposures to low RH daily until the plants became hardened (Marín 2003). Plants were exposed outside the tunnel at greenhouse RH (50\%-60\%) for increasing periods of time (from $10 \mathrm{~min}$ to $90 \mathrm{~min}$ ) lasting acclimatization approximately one to one and a halve months. This method was compared with acclimatization in a growth chamber with a precise control of the environmental conditions $\left(24{ }^{\circ} \mathrm{C}, 400 \mu \mathrm{mol} \mathrm{m}{ }^{-2} \mathrm{~s}^{-1}\right.$ PAR from cool white fluorescent lamps, and $70 \% \mathrm{RH})$.

Grafting acclimatized shoots

Acclimatized micropropagated AD15 (P. vera) plants matched the size of 4-week old terebinth rootstock seedlings. Scions $(\mathrm{n}=46)$ containing a lateral bud from the acclimatized plants were cut in $\mathrm{v}$-shape and fitted onto vertical slits made on top of decapitated seedlings (cleft grafting). Mechanical fixation of the grafting area was achieved with a thin silicon tube ( $2 \mathrm{~mm}$ inner diameter). Shoot apices of terebinth seedlings $(n=12)$ were grafted in the same way (homografts) as controls. Graft evaluations were made at 1 and 3 weeks after grafting when buds resumed growth, and survival rates were calculated.

Grafting ex vitro (in vitro shoot tips)

Due to the lack of rooting capability of some cultivars, we tested an alternative grafting technique using as scions shoot tips grown in vitro. Rootstock seedlings were prepared in a similar way. Shoot-tip scions from in vitro cultures of the female cultivars 'Larnaka' and 'Kerman' and the male cultivar 'Peters' (n ranged from 33 to 37 grafts per cultivar) were cut in v-shape and fitted onto vertical slits of decapitated rootstocks four weeks after germination. Mechanical fixation of the graft was made as above. Grafted plants should then be acclimatized as described above. Survival percentages were recorded. In vitro grown shoot-tips of terebinth were too thin to be grafted onto terebinth seedlings preventing the realization of control grafts.

Data analysis

A Student t-test was used to analyze shoot length data, whereas count data were analyzed by regression using generalized linear models (GLM) for Poisson fitted data (shoot number) or for binomial data (rooting). In addition, the prop.test for proportion data was used for shoot quality and for successful grafts data. R statistical package (R Core Team 2013) was used.

Results

Effect of antioxidant treatments on the establishment of in vitro culture of pistachio cultivars

Initial trials with forced sprouts of the different cultivars that were treated for short periods in an antioxidant solution (a mixture of ascorbic acid and citric acid, both at $1 \mathrm{mM}$ ) before surface disinfestation, did not succeed and the explants browned and died few days after inoculation. However, cultures initiated with explants taken from field-grown trees and treated for $7 \mathrm{~h}$ in the same antioxidant solution allowed starting cultures from the cultivars 'Kerman', 'Larnaka', and 'Peters', but not from 'CEspecial'. Both disinfectants used, a diluted bleach and an $\mathrm{HgCl}_{2}$ solution, were equally effective and contamination was low (from $5 \%$ to $40 \%$, depending on both disinfectant and cultivar), not showing important differences in the percentages of dead explants that were close to $50 \%$. Although many of the explants died, some developed new shoots, ranging from 6-10 \% in'Peters' to $44-27 \%$ in 'Larnaka', depending on the disinfectant (diluted bleach or $\mathrm{HgCl}_{2}$ ), and the cultures, later, developed adequately. ' $\mathrm{C}$ Especial' also developed new shoots, but they were not healthy and eventually died. The initiation of ' $\mathrm{C}$ - 
Especial' was repeated the next spring increasing the length of the antioxidant treatment from 7 to $24 \mathrm{~h}$ with better results, raising the percentage of explants developing new shoots up to $42 \%$ (Supplementary file 1) and improving shoot quality, however, cultures did not provide enough shoots for rooting experiments. On the other hand, the explants of selection AD15 taken from a field grown tree gave a better response, and one third of them developed new shoots, not needing extended antioxidant treatments.

Effect of cytokinins on shoot health

During multiplication many shoots stopped growing and/or the apex turned brown. This fact was more frequent in longer shoots, but it also affected short ones, impeding their adequate multiplication. While all cultivars were affected, AD15 shoots showed a better growth in vitro, supplying enough shoots for subsequent studies. Replacing BAP by a combination of $m \mathrm{~T}$ at $5 \mu \mathrm{M}$ and kinetin at $2 \mu \mathrm{M}$ improved shoot quality and length $(p<0.001)$, increasing the amount of healthy shoots $(p<0.001)$ (Fig. 1, A,B). However, no significant differences were found on multiplication rates (Fig. 1, C). Similarly, 'Larnaka', 'Kerman' and 'Peters' improved shoot quality with $m T$, giving multiplication rates of $2.8( \pm 0.21), 2.3( \pm 0.18)$ and $1.7( \pm 0.13)$ respectively and this rate was maintained during subcultures. No loss of shoot quality was observed with time, keeping STN low (about $20 \%$ ).

Fig. 1

Comparison of the effects of the cytokinins BAP or $\mathrm{mT}+$ kinetin, added in the multiplication medium, on A) shoot length (mm), B) percentage of healthy shoots and C) multiplication (number of shoots/shoot) in AD15 selection cultures
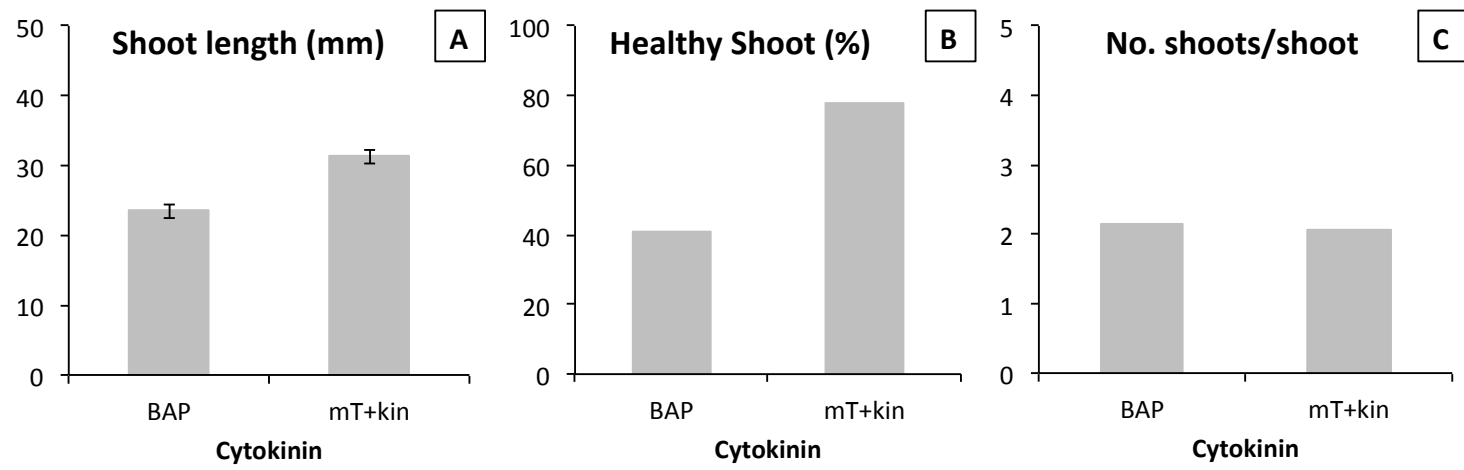

Effect of different factors on rooting

While no rooted shoots of the selection AD15 were obtained with the standard medium (control), the different factors tested yielded variable rooting percentages ranging from $3.3 \%$ to $83.3 \%$ (Fig. 2). Thus, the use of vented jars or the addition of kinetin gave very poor rooting results not statistically significant, and with no beneficial effect on shoot quality. Conversely, both phloroglucinol and Vitamin E improved rooting of shoots moderately and these effects were statistically significant $(p<0.001$, Table 1$)$. However, shoot quality was poor and rooted shoots were not suitable for acclimatization. On the other hand, paclobutrazol significantly improved rooting up to $83.3 \%$ ( $p<0.001$, Table 1 ). Roots appeared with synchrony and shoots were healthier and could be transplanted to soil. 
Fig. 2

Effect of several factors: aeration, kinetin, phoroglucinol, $\propto$-tocopherol and paclobutrazol on rooting rates $(\%)$ in $\mathrm{AD} 15$ selection

\section{Rooting (\%)}

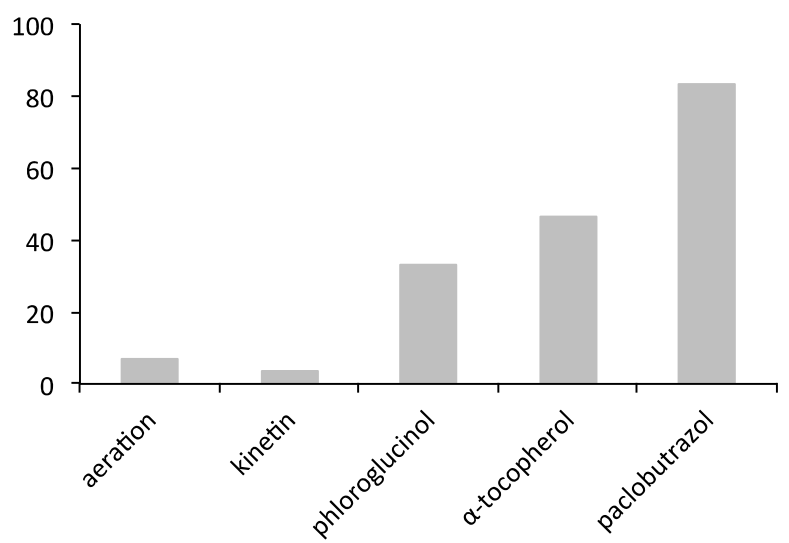

Table 1

Analysis of Deviance table of the effect of different factors on rooting of AD15 (*** significant at $\mathrm{P}<0.001$ level)

\begin{tabular}{llllll}
\hline & Df & Deviance & Resid. Df & Resid. Dev & $\operatorname{Pr}(>$ Chi $)$ \\
\hline NULL & & & 17 & 98.599 & \\
paclobutrazol & 1 & 47.964 & 16 & 50.636 & $4.342 \mathrm{e}-12 * * *$ \\
$\propto$-tocopherol & 1 & 17.639 & 15 & 32.997 & $2.671 \mathrm{e}-05 * * *$ \\
phloroglucinol & 1 & 17.827 & 14 & 15.170 & $2.419 \mathrm{e}-05 * * *$ \\
aeration & 1 & 1.438 & 13 & 13.732 & 0.2304 \\
kinetin & 1 & 1.403 & 12 & 12.328 & 0.2362 \\
\hline
\end{tabular}

The beneficial effect of paclobutrazol was further improved increasing its concentration and the effect was highly significant ( $<<0.001$, Supplementary file 2 ) following a regression analysis (Fig. 3). Rooting raised up to $96.7 \%$.

Fig. 3

Effect of different palclobutrazol concentrations: 0, 3.4 and $6.8 \mu \mathrm{M}$, on rooting rates (\%) in AD15 selection

\section{Rooting (\%)}

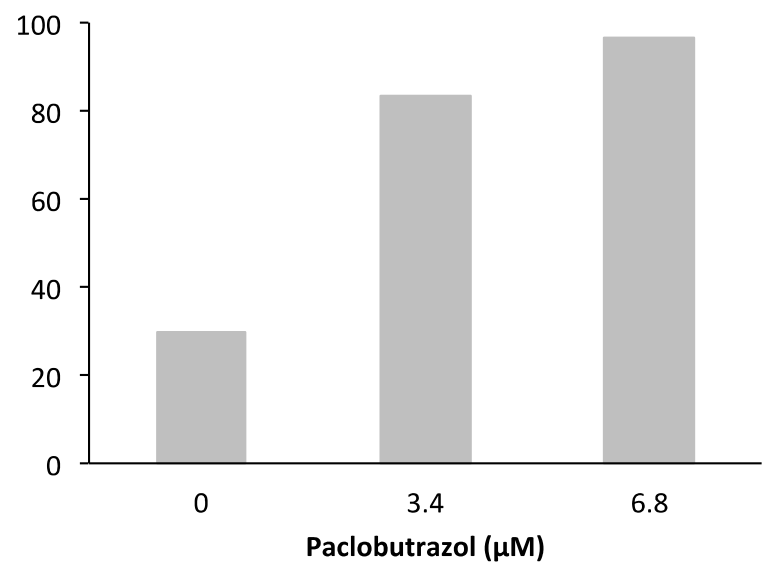


Regarding the effect on pistachio cultivars, the different treatments are shown in Table 2. Rooting was very poor, except in cultivar 'Peters', where rooting percentages ranged from $6.8 \%$ to $10.3 \%$ depending on the paclobutrazol concentration (Table 2). However, no significant differences were found between them.

Table 2

Effect of paclobutrazol concentration on rooting of pistachio cultivars

\begin{tabular}{ccccccc}
\hline $\begin{array}{c}\text { Paclobutrazol } \\
(\mu \mathrm{M})\end{array}$ & \multicolumn{2}{c}{ Peters } & \multicolumn{2}{c}{ Kerman } & \multicolumn{2}{c}{ Larnaka } \\
\hline & $\mathrm{n}$ & Rooted & $\mathrm{n}$ & Rooted & $\mathrm{n}$ & Rooted \\
0.0 & 16 & 0 & 4 & 0 & 6 & 0 \\
3.4 & 205 & 14 & 9 & 1 & 31 & 1 \\
6.8 & 300 & 31 & 13 & 2 & 97 & 2 \\
\hline
\end{tabular}

Healthy rooted shoots of selection AD15 were transplanted to soil and acclimatized in the greenhouse under a plastic tunnel. Pistachio leaves did not show wilting symptoms, so high survival percentages were only obtained following a defined schedule of daily increased exposures to low RH. When acclimatization was performed in plastic enclosures inside a culture chamber with precise environmental controls, survival rose from the initial $10 \%$ to $80 \%$. Acclimatized plants were then subcultured to pots and stem sections with one lateral bud were used as scions.

Grafting

Scions from acclimatized AD15 plants grafted onto 4 week-old potted terebinth seedlings, soon developed new shoots in $61 \%$ of the grafts (Fig. 4, 5A). This rate was similar to that of the homografts used as controls $(66.7 \%)$. Acclimatized plants supplied new scions, since lateral buds sprouted up.

Fig. 4

Succesfull grafts (\%) following ex vitro grafting of either acclimatized AD15 scions or in vitro shoot tips from 'Larnaka', 'Kerman', and 'Peters' cultivars

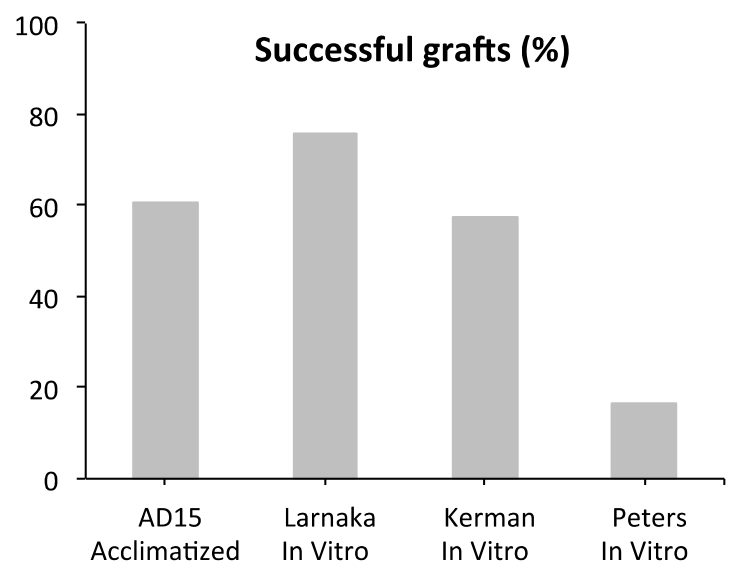


Fig. 5 Pistachio plants following ex vitro grafting onto terebinth roostock seedlings using A) acclimatized shoots scions of AD15 or B) in vitro grown shoot tips of Kerman cultivars, both one week after grafting. Ex vitro grafting of 'Larnaka' cultivar grown for C) one month, and D) three months
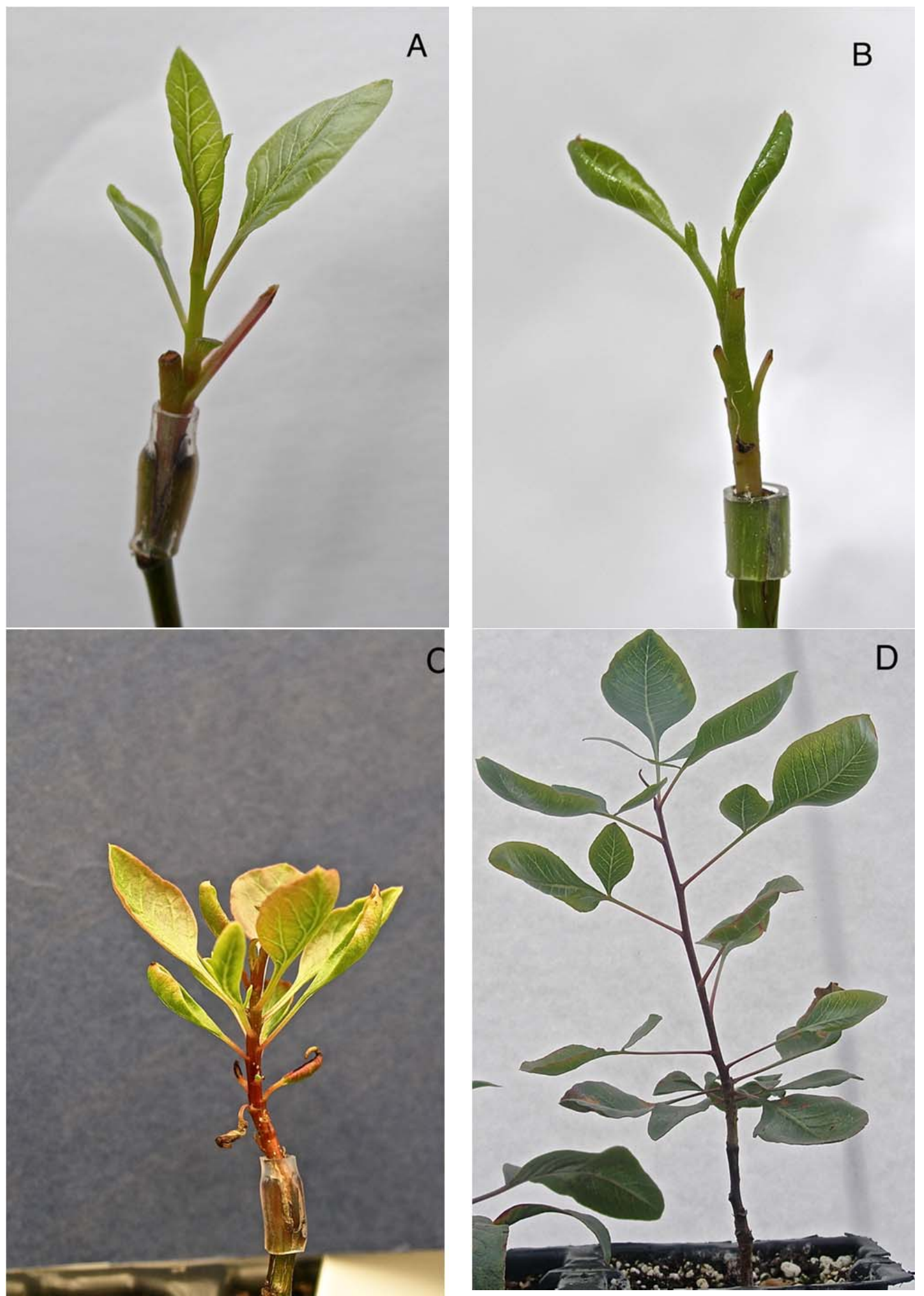

The lack of rooting capability and the poor quality of rooted shoots of the different pistachio cultivars prompted us to test cleft grafting using non-acclimatized shoot tips grown in vitro as scions. One day after grafting, during acclimatization, symptoms of failure can be identified as dryness of the scion 
together to higher susceptibility to fungal infections. Three days after grafting successful grafts remained green and turgid and new leaves start to grow. One week later scions grew normally and later the mechanical fixations were removed after one month. Successful graft percentages, following this method, were comparable to those of the acclimatized AD15 plants for 'Larnaka' and 'Kerman' with no significant differences (Fig. 4, 5B-D). However, 'Peters' showed significantly lower successful grafts $(\mathrm{P}<0.001)$. Plants grafted in this way had to suffer an acclimatization process since scions have to harden to adapt to the outside. However, acclimatization was faster an easier than with micropropagated rooted plants, lasting one or two weeks, during which grafted shoot tips resumed growth from day 3 .

\section{Discussion}

This paper describes a technique that improves pistachio grafting with a high rate of success.. We propose grafting reduced size scions of some of the main commercial cultivars obtained by in vitro culture onto potted rootstock seedlings, few weeks after germination. In this way, plants resume growth few days after grafting and can be transplanted to the field three months later. Moreover, this method allows us to use directly shoot tips growing in vitro as scions, thus avoiding the rooting and acclimatization stages which have proved difficult with the cultivars used here. This type of grafting adds flexibility to the propagation method of pistachio avoiding main grafting problems such as grafting delay, grafting uncertainty or frequent re-grafting.

Micropropagation of mature cultivars has been achieved for 'Kerman', 'Larnaka', 'Peters', and AD15 selection, but a number of problems during the process have been overcome. We confirmed our initial hypotheses about (1) the beneficial effect of prolonged treatments with antioxidants on culture initiation; (2) the improvement of shoot quality and the reduction of STN by the substitution of BAP for $m$ T + kinetin during multiplication stage; and (3) the favorable effect of paclobutrazol, an inhibitor of GA synthesis, on rooting. Other tested factors had only moderate or no beneficial effect on rooting, as the enhancement of leaf transpiration by aeration, the addition of the antioxidants vitamins $\mathrm{C}$ and $\mathrm{E}$ or phloroglucinol. The application of these factors allowed us getting valuable scions directly from in vitro cultures.

Pistachio, as other woody plants, tends to turn brown, mainly during the establishment of the culture, staining brown also the medium. This causes the early death of the explants, and different solutions have been tested with uneven results (Chatibi et al. 1997; Dolcet-SanJuan and Claveria 1995; Leng et al. 2009). Browning has been correlated directly with PPO activity in bamboo; however, no relation with the endogenous phenolic content was found (Huang et al. 2002). On the contrary, tissues of P. vera in vitro showed a positive correlation between phenolic content and browning, but no changes in the activity of PPO was found (Leng et al. 2009). Browning has been described as the result of the activity of catechol oxidase (a PPO enzyme) that produces highly reactive quinones from phenolic compounds (Mayer and Harel 1979; Walker and Ferrar 1998) and the oxidation of phenols can be inhibited by the presence of antioxidants as ascorbic acid (Mayer and Harel 1979). In 'Golden Delicious' apple cubes, when the cubes were dipped for $5 \mathrm{~min}$ in solutions of ascorbic acid and citric acid, a 90-100\% PPO inhibition was found, being maximum at 10 gl-1 ascorbic acid + 2 gl-1 citric acid (Pizzocaro et al. 1993). We have successfully used a mixture of ascorbic acid and citric acid both at $1 \mathrm{mM}$ that controlled explants browning and permitted the establishment of all the cultivars tested simply by varying the time of antioxidant treatment. The lower concentrations used here might be compensated by longer treatment periods depending on the cultivar. While the selection AD15 grew well after just 15 min of treatment, the rest of the cultivars did not. 'Kerman', 'Larnaka' and 'Peters' were treated for $7 \mathrm{~h}$, and the treatment had to be extended to $24 \mathrm{~h}$ for 'C-Especial'. In addition, this antioxidant treatment had to be complemented with frequent transfers of the explants to fresh medium with a lower concentration of ascorbic acid $(55.6 \mu \mathrm{M})$ to avoid the toxicity of the exudates.

STN is an unwanted and common feature as shoots grow at multiplication stage of numerous species including Pistacia. In P. vera shoots cultured in vitro in MS medium (Murashige and Skoog 1962) STN was reduced notably when the culture medium was supplemented with Ca or B (Barghchi and Alderson 1996). We observed a similar effect (García et al. 2011b) when P. vera shoots were cultured in Caenriched mineral formulations as DKW medium, instead of MS or WPM (Lloyd and McCown 1981) media. However, further supplements of $\mathrm{Ca}$ in the form of Ca-gluconate did not show an additional reduction of STN. On the other hand, good results in improving shoot quality have been achieved here by the use of the $m \mathrm{~T}$ and kinetin citokinins instead of BAP. Similarly, a positive effect on shoot quality 
replacing BAP by $m \mathrm{~T}$ has been found in Harpagophytum procumbens (Bairu et al 2009a) and P.vera (Benmahioul et al. 2012). The role of plant growth regulators (PGR) on STN has been reviewed by Bairu et al. (2009b); both auxins and cytokinins play a role in STN, affecting negatively with concentration, although their use is necessary for plant growth. The use of topolins, especially $m \mathrm{~T}$ and its derivatives, has expanded in recent years applied to a growing list of species at different concentrations (Aremu et al. 2012). Here, in mature $P$. vera shoots, the substitution of BAP with $m \mathrm{~T}$ at the same concentration $(5 \mu \mathrm{M})$, supplemented with Kin $(2 \mu \mathrm{M})$ to offset the lower number of shoots produced by $m$ T compared to BAP (Werbrouk et al. 1996), increased significantly shoot quality, with longer shoots, less affected by STN, and without a reduction in shoot multiplication. A different approach has been reported by Akdemir et al. (2014) with a remarkable success in reducing STN of juvenile and adult pistachio plants using temporary immersion systems that should be taken into account with our cultivars.

During rooting phase $P$. vera displayed different problems as lack of rooting, delayed root formation and lack of synchrony or shoot decay and STN (Benmahioul et al. 2012; Chatibi et al. 1997; Tilkat and Onay 2009). Here, we have faced these problems 1) trying to keep shoot health during rooting increasing aeration; 2) adding auxin protective compounds; and 3) adding paclobutrazol to inhibit GA biosynthesis and reducing its negative effect on root formation. Applications in this work of antioxidants as auxin protective compounds and, even further, the inhibition of GA biosynthesis, by paclobutrazol application, dramatically increased Pistacia rooting rates from $10.3 \%$ to $96.7 \%$ and these roots appeared with synchrony while shoots were healthier and easier to acclimatize.

Trying to keep shoot health during rooting, aeration was increased inside the jars. As we have described previously aeration produced with vented jars, and other factors that improved transpiration, as bottom cooling or a reduced number of shoots per jar, reduced STN during multiplication of shoots of $P$. vera (García et al. 2011b). However, no effect, either on shoot quality or rooting rates, was observed here during rooting phase.

The protection of natural auxins against the enzyme IAA-oxydase may enhance rooting, since auxins can act at higher concentrations and stimulate root formation. Both antioxidants $\propto$-tocopherol and phloroglucinol were added to rooting medium showing an effect on rooting. Phoroglucinol, together with natural auxins as IAA or IBA, but not with the synthetic auxin NAA, had a protective effect against decarboxylation by IAA-oxydase, as described by De Klerk et al. (2011) with thin apple stem discs. Phloroglucinol had, in this work, a moderate effect on rooting of AD15 shoots (33\% rooted shoots) when included at $0.79 \mathrm{mM}$ in a rooting medium with IBA $(5 \mu \mathrm{M})$, however, roots appeared with delay and

shoot-tips became necrotic. Besides, the lipophilic antioxidant $\propto$-tocopherol (vitamin E) increased rooting (46.7\% rooted AD15 shoots), but roots appeared also with delay and shoot-tips became necrotic.

Best results in rooting were obtained here with the addition of paclobutrazol $(3.4 \mu \mathrm{M})$ to the rooting medium. Up to $83.3 \%$ or $13.3 \%$ rooted shoots were obtained respectively with mature AD15 shoots or 'Peters'. However, lower rooting rates were achieved with 'Larnaka' and 'Kerman'. This positive effect was even increased when paclobutrazol was added at a higher concentration $(6.8 \mu \mathrm{M})$; moreover, roots appeared with synchrony and shoots remained healthy in most of AD15 shoots. Some unexpected rooting percentages were found like in control shoots without paclobutrazol $(30 \%)$ that can be explained in terms of a change in the rooting capability occurred during culture, since the experiment was delayed in time from the previous experiment where control shoots did not root. The effect of paclobutrazol on rooting, first reported in Plectranthus australis cuttings and Phaseolus vulgaris hypocotils (Davis et al. 1985), was soon tested on fruit trees with unequal results (Marino 1988). It improved rooting of the pear cultivar 'Abbé Fetel' and a hybrid Prunus rootstock selection (S749 x S1490), but not of the sour cherry rootstock CAB 11E (Prunus cerasus L). Paclobutrazol, a triazole, inhibits the synthesis of GA by blocking the Cytochrome P450, involved in biosynthetic reactions leading to different compounds as plant growth regulators (GA, ABA and cytokinins) (Grossmann 1990). The application of paclobutrazol to culture medium exhibit a varied range of effects, as the enhancement of cytokinin-induced effect on shoot proliferation in Spatiphyllum floribundum (Werbrouck and Debergh 1996), the strong reduction of nodal sprouting in apricot and neem (Padilla et al. 2015), or the induced reduction of internode length of pea (Ribalta et al. 2014). The GA inhibitor effect of paclobutrazol seems to be responsible of the rooting promoting effect found here, since GA reduced the induction of root primordia (Haissig 1972). Here, we show for the first time a positive effect of placlobutrazol on Pistacia cultures, clearly improving AD15 rooting. While 'Peters' also showed a beneficial effect of paclobutrazol on rooting, more work is needed to determine its effect on 'Kerman' and 'Larnaka', since lack of material conditioned sample size.

However, a genotype dependent effect is also possible. 
Micropropagation has been satisfactorily used in this work to obtain reduced size scions in order to allow earlier grafting of terebinth rootstocks. On the one side, acclimatized AD15 plants, grown in pots in the greenhouse, supplied suitable scions, consisting in nodes with a lateral bud, for grafting 4-weeks old terebinth seedlings. Grafting success reached $61 \%$ improving most conventional results that ranged, in our main production area, from $33 \%$ to $68 \%$ depending on the diameter of the rootstock (10 to $15 \mathrm{~mm}$; Guerrero et al. 2007a), and anticipating grafting two years (Atli et al. 2001). In addition, once trimmed, acclimatized plants can supply new scions, since new shoots develop from lateral buds, which assure scion availability.

These satisfactory results were later improved with the use of non-acclimatized in vitro grown shoot tips as scions. Grafting success rates of 'Kerman' and 'Larnaka' shoot-tips were not significantly different than that of acclimatized AD15 scions, proving rooting unnecessary, what eliminates one of the more difficult steps of tissue culture. The use of in vitro shoot tips directly makes the grafting technique simpler. Here, ex vitro grafting of in vitro shoots has been successfully applied in Pistacia propagation for the first time, since only micrografting had been attempted with 'Mateur' or 'Siirt' cultivars (Abousalim and Mantell 1992; Onay et al. 2004, 2007) with uneven results. On the contrary, in vivo grown scions grafted onto in vitro seedlings failed. This was explained either for notable differences in size between rootstock and scion, preventing graft union or for incompatibility between scions and rootstock (Can et al. 2006). Ex vitro grafting has been successfully applied with juvenile material in several species, mainly as a technique to rescue transgenic rootless shoots in Citrus (Yang et al. 2000) or Helianthus (Weber et al. 2003). Likewise, the technique allowed the rescue of somatic embryos lacking root system in avocado (Raharjo and Litz 2005).

Despite the encouraging results with 'Kerman' or 'Larnaka' cultivars, grafting success rates within the cultivar 'Peters' were significantly lower. These results might indicate the need of adjustments in the tissue culture technique of this cultivar, but can also indicate other kind of problems more closely related to the graft compatibility mechanisms in place. The rate of grafting success with homografts of terebinth seedlings, used here as control, was similar to that reached with cultivars 'Kerman' or 'Larnaka' or the AD15 selection showing no incompatibility problems for these cultivars. Moreover, this technique provides the advantage that we can take the plants that show good growth at a very early step, since scions resumed growth few days after grafting. Propagation of pistachio based on grafting should be improved to match results obtained with other fruit trees and to improve and accelerate plant production; however, no studies on rootstock/scion compatibility have been reported yet in pistachio. In this context, the technique described here can help supplying a good and novel experimental model for such assessments. This technique can be an alternative to conventional propagation provided there is a satisfactory performance of grafted plants in the field. In addition, this technique can be extended to other rootstocks, either propagated by seeds or by micropropagation. To our knowledge, this is the first time that ex vitro grafting of shoot-tips, grown in vitro from mature plants, have been used for propagation purposes.

Acknowledgements

This work was partly funded by the Instituto Nacional de Investigación y Tecnología Agraria y Alimentaria-FEDER RTA2014-00056-C02 project and by Group A-43 grant by the Government of Aragon. Substrate was kindly provided by Pindstrup Mosebrug S.A.E. (Sotopalacios, Spain).

\section{References}

Abousalim A, Mantell SH (1992) Micrografting of pistachio (Pistacia vera L. cv. Mateur). Plant Cell Tissue Organ Cult 29: 231-234

Abousalim A, Mantell SH (1994) A practical method for alleviating shoot-tip necrosis symptoms in in vitro shoot cultures of Pistacia vera cv Mateur. J Hortic Sci 69: 357-365

Akdemir H, Süzerer V, Onay A, Tilkat E, Ersali Y, Çiftçi YO (2014) Micropropagation of the pistachio and its rootstocks by temporary immersion system. Plant Cell Tissue and Organ Cult 117: 65-76 
Aremu AO, Bairu MW, Dolezal K, Finnie JF, Van Staden J (2012) Topolins: A panacea to plant tissue culture challenges? Plant Cell Tissue Organ Cult 108: 1-16

Atli HS, Arpaci S, Ayanoglu H (2001) Comparison of seedling characteristics of some Pistacia species. Options Méditerranéennes 56: 215-218

Bairu MW, Jain N, Stirk WA, Doležal K, Van Staden J (2009a). Solving the problem of shoot-tip necrosis in Harpagophytum procumbens by changing the cytokinin types, calcium and boron concentrations in the medium. S Afr J Bot 75: 122-127

Bairu MW, Stirk WA, Van Staden J (2009b) Factors contributing to in vitro shoot-tip necrosis and their physiological interactions. Plant Cell Tissue Organ Cult 98: 239-248

Barghchi M, Alderson PG (1996) The control of shoot tip necrosis in Pistacia vera L. in vitro. Plant Growth Reg 20: 31-35.

Benmahioul B, Dorion N, Kaid-Harche M, Daguin F (2012) Micropropagation and ex vitro rooting of pistachio (Pistacia vera L.). Plant Cell Tissue Organ Cult 108: 353-358

Can C, Ozaslan M, Toremen H, Sarpkaya K, Iskender E (2006) In vitro micrografting of pistachio, Pistacia vera L. var. Siirt, on wild pistachio rootstocks. J Cell Mol Biol 5:25-31

Chatibi A, Kchouk ML, Mliki A, Zemmi H, Ghorbel A (1997) Use of growth regulators for adventitious shoot regeneration and plant propagation from mature cotyledon of pistachio (Pistacia vera L.). Acta Hortic 441: 263-269

Davis TD, Sankhla N, Walser RH, Upadhyaya A (1985) Promotion of adventitious root-formation on cuttings by paclobutrazol. HortScience 20: 883-884

De Klerk GJ, Guan H, Huisman P, Marinova S (2011) Effect of phenolic compounds on adventitious root formation and oxidative decarboxylation of applied indoleacetic acid in Malus 'Jork 9'. Plant Growth Reg 631: 175-185.

Dolcet-San Juan R, Clavería E (1995) Improved shoot-tip micropropagation of Pistacia vera L. and the beneficial effects of methil jasmonate. J Am Soc Hortic Sci 120: 938-942

Driver JA, Kuniyuki AH (1984) In vitro propagation of Paradox walnut rootstock. HortScience 19: 507509.

Ferguson L, Sanden B, Grattan S, Epstein L, Krueger B (2005) Pistachio rootstocks. In Ferguson L, Beede RH, Freeman MW, Haviland DR, Holtz BA, Kallsen C E (eds). Pistachio production manual. Fruit and Nut Research and Information Center, 4th edn. University of California, Davis, pp 67-73

García E, Imbroda I, Lorente P, Marín JA, Arbeloa A, Padilla IMG, Barceló A, Andreu P (2011a) Micropropagation and in vitro grafting techniques to assist the selection of a pistachio rootstock from a population of terebinth (Pistacia terebinthus L.) collected in the SE of Spain. Acta Hortic 961:245252

García E, Lorente P, Marín JA, Andreu P, Arbeloa A (2011b) Factors affecting shoot tip necrosis of Pistacia vera L. shoots cultured in vitro. ITEA 107:315 -323

Grossmann K (1990) Plant growth retardants as tools in physiological research. Physiol Plant 78:640-648

Guerrero J, Couceiro JF, Moriana A (2002) Selection of Terebinth (Pistacia terebinthus L.) trees as seed producers for pistachio (Pistacia vera L) rootstocks in the Castilla La Mancha (Spain). FAO-Nucis-Newsl 11: $25-29$

Guerrero J, Couceiro JF, Gijón MC, Moriana A, Rivero A (2007a) El injerto de yema en "Pistacia terebinthus" L. (Pistacia vera L.): la influencia del vigor y la procedencia. Fruticultura Profesional 169: 48-54 
Guerrero J, Couceiro JF, Moriana A, Gijon MC Rivero A (2007b) El pistachero (P. vera L.) en CastillaLa Mancha. Comportamiento en secano de diferentes cultivares y portainjertos. Actas Horticultura 48: 635-638

Haissig BE (1972) Meristematic activity during adventitious root primordium development: Influences of endogenous auxin and applied gibberellic acid. Plant Physiol 49: 886-892.

Huang LC, Lee YL, Huang BL (2002) Polyphenol oxidase activity and low titratable acidity in browning bamboo tissue culture. In Vitro Cell Dev Biol-Plant 38: 358-366

Leng P, Su S, Wei F, Yu F, Duan Y (2009) Correlation between browning, total phenolic content, polyphenol oxidase and several antioxidation enzymes during pistachio tissueculture. Acta Hortic 829: 127-131

Lis-Balchin M (1989) The use of antioxidants as rooting enhancers in the Geraniceae. J Hortic Sci 64: 617-623

Lloyd G, McCown B (1981) Commercially-feasible micropropagation of mountain laurel, Kalmia latifolia, by use of shoot-tip culture. Comb Proc Int Plant Propag Soc 30: 421-427.

Long MN, Preece JE, Van Sambeek W (1995) Adventitious regeneration of Juglans nigra L. (eastern black walnut) Lynn M. Plant Cell Rep 14: 799-803

Marín JA (2003) High survival rates during acclimatization of micropropagated fruit tree rootstocks by increasing exposures to low relative humidity. Acta Hortic 616: 139-142

Marín JA, García E, Lorente P, Arbeloa A, Andreu P (2015) Propagation of pistachio applying in vitro culture techniques. Acta Hortic (in press)

Marino G (1988) The effect of paclobutrazol on in vitro rooting, transplant establishment and growth of fruit plants. Plant Growth Regul 7: 237-247

Mayer AM, Harel E (1979) Polyphenol oxidase in plants. Phytochem 18: 193-215.

Murashige T, Skoog F (1962) A revised medium for rapid growth and bioassays with tobacco tissue cultures. Physiol Plant 15: 473-497.

Onay A (2000) Micropropagation of Pistachio from mature trees. Plant Cell Tissue Organ Cult 60: 159_ 162

Onay A, Virinç V, Yildirim H, Basaran D (2004) In vitro micrografting of mature pistachio (Pistacia vera var. Siirt). Plant Cell Tissue Organ Cult 77:215-219

Onay A, Tilkat E, Isikalan C, Namli S (2007) Micrografting of Pistachio (Pistacia vera var 'Siirt'. In: Protocols for Micropropagation of Woody Trees and Fruits, Jain SM, Häggman H (eds) Springer, Dordrecht, pp: 289-298

Padilla IMG, Fernandez-García N, Olmos E, Burgos L, Piqueras A (2015) Effects of growth retardants on sprouting and development of apricot (Prunus armeniaca L.) and neem (Azarchta indica A. Juss.) nodal buds. Plant Cell Tissue Organ Cult doi: 10.1007/s11240-015-0765-8

Pizzocaro F, Torreggiani D, Gilardi G (1993) Inhibition of apple polyphenoloxidase (PPO) by ascorbic acid, citric acid and sodium chloride. J Food Process Preserv 17: 21-30

R Core Team (2013) R: A language and environment for statisticalcomputing.

R Foundation for Statistical Computing, Vienna, Austria.http:/www.R-project.org/

Raharjo SHT, Litz RE (2005) Micrografting and ex vitro grafting for somatic embryo rescue and plant recovery in avocado (Persea americana). Plant Cell Tissue Organ Cult 82: 1-9 
Ribalta FM, Croser JS, Erskine W, Finnegan PM, Lulsdorf MM, Ochatt SJ (2014) Antigibberellininduced reduction of internode length favors in vitro flowering and seed-set in different pea genotypes. Biol Plant 58: 39-46

Tabiyeh DT, Bernard F, Shacker H (2006) Investigation of glutathione, salicylic acid and $\mathrm{GA}_{3}$ effects on browning in Pistacia vera shoot tips culture. Acta Hortic 726: 201-204

Tilkat E, Onay A (2009) In Vitro Rooting Improvement of Adult Pistachio, Pistacia vera L. 'Atli'. Acta Hortic 839: 215-223.

Walker JRL, Ferrar PH (1998) Diphenol oxidases, enzyme-catalysed browning and plant disease resistance. Biotechnol Genet Eng Rev 15: 457-498

Weber S, Friedt W, Landes N, Molinier J, Himber C, Rouselin P, Hahne G, Horn R (2003) Improved Agrobacterium-mediated transformation of sunflower (Helianthus annus L.) assessment of macerating enzymes and sonication. Plant Cell Rep 21: 475-482

Werbrouck SPO, Debergh PC (1996) Imidazole fungicides and paclobutrazol enhance cytokinin-induced adventitious shoot proliferation in Araceae. J Plant Growth Regul 15: 81-85

Werbrouck SPO, Strnad M, VanOnckelen HA, Debergh PC (1996) Meta-topolin, an alternative to benzyladenine in tissue culture? Physiol Plant 98:291-297

Yang ZN, Ingelbrecht IL, Louzada E, Skaria M, Mirkov TE (2000) Agrobacterium-mediated transformation of the commercially important grapefruit cultivar Rio Red (Citrus paradisi Macf.). Plant Cell Rep 19: 1203-1211 